\title{
Counting skills intervention for low-performing first graders
}

\begin{tabular}{|c|c|}
\hline \multicolumn{2}{|c|}{$\begin{array}{l}\text { Authors: } \\
\text { Riikka Mononen } \\
\text { Pirjo Aunio } \\
\text { 2,3 }\end{array}$} \\
\hline \multicolumn{2}{|c|}{$\begin{array}{l}\text { Affiliations: } \\
{ }^{1} \text { Department of Special } \\
\text { Needs Education, University } \\
\text { of Oslo, Norway }\end{array}$} \\
\hline \multicolumn{2}{|c|}{$\begin{array}{l}{ }^{2} \text { Department of Childhood } \\
\text { Education, University of } \\
\text { Johannesburg, South Africa }\end{array}$} \\
\hline \multicolumn{2}{|c|}{$\begin{array}{l}{ }^{3} \text { Department of Teacher } \\
\text { Education, Special Education, } \\
\text { University of Helsinki, Finland }\end{array}$} \\
\hline \multicolumn{2}{|c|}{$\begin{array}{l}\text { Corresponding author: } \\
\text { Riikka Mononen, } \\
\text { r.m.mononen@isp.uio.no }\end{array}$} \\
\hline \multicolumn{2}{|c|}{$\begin{array}{l}\text { Dates: } \\
\text { Received: } 03 \text { Mar. } 2016 \\
\text { Accepted: } 05 \text { July } 2016 \\
\text { Published: } 23 \text { Sept. } 2016\end{array}$} \\
\hline \multicolumn{2}{|c|}{$\begin{array}{l}\text { How to cite this article: } \\
\text { Mononen, R. \& Aunio, P., } \\
\text { 2016, 'Counting skills } \\
\text { intervention for low- } \\
\text { performing first graders', } \\
\text { South African Journal of } \\
\text { Childhood Education 6(1), } \\
\text { a407. http://dx.doi. } \\
\text { org/10.4102/sajce.v6i1.407 }\end{array}$} \\
\hline \multicolumn{2}{|c|}{$\begin{array}{l}\text { Copyright: } \\
\text { C 2016. The Authors } \\
\text { Licensee: AOSIS. This } \\
\text { is licensed under the } \\
\text { Creative Commons } \\
\text { Attribution License. }\end{array}$} \\
\hline \multicolumn{2}{|l|}{ Read online: } \\
\hline 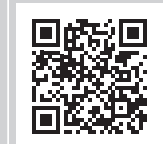 & $\begin{array}{l}\text { Scan this QR } \\
\text { code with your } \\
\text { smart phone or } \\
\text { mobile device } \\
\text { to read online. }\end{array}$ \\
\hline
\end{tabular}

Background: It is important to provide early educational support for children having weak mathematical skills, in order to prevent possible later mathematical learning difficulties. Currently, there is a lack of research-based mathematical intervention programmes for teachers to use.

Aim: This study investigated the impact of counting skills intervention for Finnish first graders with low performance. In addition, the relations between inductive reasoning, language and mathematical skills were examined.

Setting: This study applied a quasi-experimental design using control groups.

Methods: Intervention was provided in small groups 12 times during 8 weeks. The development of intervention children (LOWi, $n=11$ ) was compared to the development of low-performing (LOWc, $n=26$ ) and typically performing (TYPc, $n=114$ ) children.

Results: The LOWi group made significantly greater gains in their mathematical performance from Time 1 to Time 2, compared with the LOWc and TYPc groups. Children with low performance in mathematical skills showed lower performance also in their inductive reasoning and reading fluency skills than the TYP children.

Conclusion: A relatively short counting skills intervention that applied explicit teaching showed promising effects in improving low-performing children's mathematical performance as a supplemental instruction.

\section{Introduction}

The performance of children in early mathematical skills varies widely, even before they begin formal schooling (Desoete et al. 2009). Previous research suggests that without adequate support, children performing low in early mathematical skills, that is, scoring at or below the 25 th percentile in mathematics tests (Geary 2013), often demonstrate continuing low mathematical performance (Morgan, Farkas \& Wu 2009). Hence, the importance of early mathematical support has been emphasised in order to prevent the emergence of possible mathematical difficulties later on. Legal and practical actions have been taken to provide educational support for all children in a country such as Finland. Accordingly, the demand for providing educators with intervention programmes with proven effectiveness in improving learning outcomes has increased.

Over the years, several different models of development of early numeracy skills have been introduced (e.g. Sarama \& Clements 2009; Wright et al. 2002). Here, we use the model of Aunio and Räsänen (2015) as it focuses especially on the core numeracy skills that are important from the viewpoint of low-performing children and as it served as a theoretical base for developing our intervention programme. According to this model, the core early mathematical skills for later development are symbolic and non-symbolic number sense (approximate evaluation of magnitudes or symbols representing magnitudes), understanding mathematical relations, counting skills and basic skills in arithmetic (for a detailed description of skills, see Aunio \& Räsänen 2015). Of these skills, kindergartners and first graders who perform low in mathematics typically have difficulties especially in counting skills, which includes number word sequence, enumeration with concrete objects and knowledge of number symbols (e.g. Toll \& Van Luit 2014), going beyond the memorised counting string that can be recited without comprehension of its numerical meaning. Difficulties in verbal and object counting may be indicated, for instance, when number words are missing in the sequence; for example, when a child counts ' $8,9,11,12$ '. Furthermore, a child may be unable to maintain one-to-one correspondence between counting words and objects and may use immature strategies in counting tasks. Longitudinal studies have shown that counting skills are a significant predictor of later arithmetical skills (e.g. Aunio \& 
Niemivirta 2010; Desoete et al. 2009). Thus, weaknesses in counting skills may delay the development of arithmetical skills and result later on as severe difficulties in basic skills in arithmetic, in other words an inability to retrieve simple calculations from long-term memory quickly, such as $3+4$ or $9-5$. Such an inability typically characterises school-aged children with mathematical learning disabilities (Jordan, Hanich \& Kaplan 2003).

Mathematics intervention studies concerning low-performing first graders is still quite limited, and most of these have been conducted in the United States (Bryant et al. 2008a; 2008b; 2011; Clarke et al. 2014; Fuchs et al. 2005; 2006; Smith et al. 2013; Yang et al. 2014). These studies with first graders have focused on improving core mathematical skills: number concept, counting skills, addition and subtraction facts learning and the place value concept. In each study, the instruction was delivered in small-group instructional format, usually from two to four times per week for 8-23 weeks, with the exception of one-to-one tutoring in the study of Smith et al. (2013). The instructional elements used in the intervention programmes included explicit teaching (Bryant et al. 2008a; 2008b; 2011; Clarke et al. 2014), using visual representations of mathematical concepts such as manipulatives and/or pictures (Bryant et al. 2008a; 2008b; 2011; Clarke et al. 2014; Smith et al. 2013; Yang et al. 2014), children's collaboration in solving story problems (Yang et al. 2014) or computer-assisted instruction (Fuchs et al. 2005; 2006). The findings in these studies showed positive effects in boosting the mathematical skills of low-performing children (except for Bryant et al. 2008a). This indicates that rather short, carefully designed programmes that take into consideration the development of mathematical skills and apply elements, such as explicit instruction, visual representations, and use of computers, are cornerstones for an effective mathematics instruction for children struggling in mathematics.

The main aim of this study was to determine whether the mathematical skills of low-performing children could be improved using the counting skills intervention programme, ThinkMath (Mononen \& Aunio 2012). To understand mathematics learning in a broader context, we also measured the children's inductive reasoning (IR) and language skills, namely reading fluency and listening comprehension skills. The research questions were as follows: How do lowperforming children receiving counting skills intervention tuition develop in their mathematical skills, compared with the children in two control groups (i.e. low-performing and typically performing children)? What are the relations between IR, language and mathematical skills?

\section{Research methods and design Participants}

In Finland, mathematics instruction is based on the Finnish national core curriculum for mathematics (Finnish National Board of Education (FNBE) 2004). During the first term of the school year, there is a focus on counting, comparison, seriation and addition and subtraction skills in the number range of $0-12$. During the second term, children usually practice addition and subtraction skills mainly in the number range 1-20. They also learn basic geometry and measurement and are introduced to numbers up to 100 at the end of the school year. First graders have three mathematics lessons of 45 minutes each per week. Organising educational support in Finland is based on three tiers: general, intensified and special support (Basic Education Act 628/1998, Amendment 642/2010; FNBE 2010), which shares similarities with the Response to Intervention (RtI) approach used in the United States (Björn et al. 2015).

The participants were 151 first graders (mean age $=7$ years 2 months, $\mathrm{SD}=3.78$ months) from nine classrooms located in three cities of Southern Finland. All the children were present at the first and second assessment time (T1 in September and $\mathrm{T} 2$ in December) of mathematical skills, but because of illness at $\mathrm{T} 1$ and/or T2, the attrition rate of children concerning IR skills was $9.9 \%$ (15 children) and that for language skills $6.6 \%$ (10 children). The number of children at the third assessment (T3 in March) was reduced by seven children (4.6\%) in mathematical and by four children in IR skills (12.6\%). All the children had written permission to participate in the study from their parents and the educational authorities of the municipalities.

In order to identify the children who performed low in mathematics, the criterion was set by scoring at or below the 25th percentile (e.g. Geary 2013) in the mathematics test at T1 (see the test description under the Measures section). According to this criterion, the intervention group (LOWi) consisted of 11 low-performing children, the low-performing control group (LOWc) consisted of 26 children and the typically performing control group (TYPc) consisted of 114 children. The children in the control groups received only regular mathematics core instruction. The children's demographic descriptives (age, gender, language and parental educational level) were collected from their parents (Table 1).

\section{Measures}

Mathematical skills: Mathematical skills were assessed using the test developed for the research project purpose, Assessment of Mathematics Skills in the First Grade (Aunio \& Mononen 2012). This group-based paper-and-pencil test includes mathematical tasks in the range from 1 to 100: (1) mathematical relational skills (i.e. number comparison); (2) counting skills (i.e. verbal and object counting) and (3) word problems (i.e. verbal addition and subtraction problems). Single-digit addition and subtraction facts in the range from 1 to 20 are also assessed (within a 2-minute time limit). A sum score for the subscales 1-3 (i.e. a combined scale) was used to identify the low-performing children. Cronbach's alpha calculations showed a high reliability for combined scale and addition and subtraction subscales at T1: for a combined scale, $\alpha=0.91$; for the addition facts scale, $\alpha=0.93$; and for the subtraction facts scale, $\alpha=0.93$. 
TABLE 1: Demographic descriptives (age, gender, language and parental educational level) by group.

\begin{tabular}{|c|c|c|c|c|}
\hline \multirow[t]{2}{*}{ Variable } & LOW & LOW & TYP & All \\
\hline & Intervention $(n=11)$ & Control $(n=26)$ & Control $(n=114)$ & $(N=151)$ \\
\hline Mean age in months (SD) & $84.27(2.76)$ & $85.88(4.18)$ & $86.50(3.73)$ & $86.23(3.77)$ \\
\hline \multicolumn{5}{|l|}{ Gender } \\
\hline Boys $n(\%)$ & $4(36.4)$ & $5(19.2)$ & $67(58.8)$ & $76(50.3)$ \\
\hline Girls $n(\%)$ & $7(63.6)$ & $21(80.8)$ & $47(41.2)$ & $75(49.7)$ \\
\hline \multicolumn{5}{|l|}{ Language } \\
\hline Finnish $n(\%)$ & $8(72.7)$ & $19(73.1)$ & $97(85.1)$ & $124(82.1)$ \\
\hline Other $n(\%)$ & $1(9.1)$ & $0(0.0)$ & $8(7.0)$ & $9(6.0)$ \\
\hline Missing information $n(\%)$ & $2(18.2)$ & $7(26.9)$ & $9(7.9)$ & $18(11.9)$ \\
\hline \multicolumn{5}{|l|}{ Mother's educational level } \\
\hline Comprehensive school $n(\%)$ & $3(27.3)$ & $3(11.5)$ & $6(5.3)$ & $12(7.9)$ \\
\hline Secondary education $n(\%)$ & $2(18.2)$ & $9(34.6)$ & $41(36.0)$ & $52(34.4)$ \\
\hline Higher education $n(\%)$ & $3(27.3)$ & $7(26.9)$ & $56(49.1)$ & $66(43.7)$ \\
\hline Missing information $n(\%)$ & $3(27.3)$ & $7(26.9)$ & $11(9.6)$ & $21(13.9)$ \\
\hline \multicolumn{5}{|l|}{ Father's educational level } \\
\hline Comprehensive school $n(\%)$ & $1(9.1)$ & $3(11.5)$ & $6(5.3)$ & $10(6.6)$ \\
\hline Secondary education $n(\%)$ & $5(45.5)$ & $11(42.3)$ & $47(41.2)$ & $63(41.7)$ \\
\hline Higher education $n(\%)$ & $2(18.2)$ & $5(19.2)$ & $47(41.2)$ & $54(35.8)$ \\
\hline Missing information $n(\%)$ & $3(27.3)$ & $7(26.9)$ & $14(12.3)$ & $24(15.9)$ \\
\hline
\end{tabular}

LOW, low-performing, TYP, typically performing.

IR skills: A set of IR skills was assessed using the test developed for the research project purpose, Assessment of Thinking Skills in the First Grade (Hotulainen, Mononen \& Aunio 2012). This group-based, paper-and-pencil test includes tasks measuring two types of IR skills (Klauer 1989): comparing attributes and comparing relations. Each item is a multiplechoice task using pictures with verbal instructions for each item. Six items (four on attributes and two on relations) did not correlate significantly with the combined scale (33 items), meaning that these items measured something other than the rest of the items in the test. After the removal of these items, the reliability of the scale increased to an acceptable level $(\alpha=0.68)$. Thus, only these 27 items were used in the analysis.

Language skills: Children's listening comprehension skills were measured using the Ytte test (Kajamies et al. 2003). The test consists of two short stories (non-fiction and fiction) with six and seven verbal claims, respectively. Each story is told twice, and after listening to one story, a child must choose whether the presented claims related to the story are true or not by marking a happy or an unhappy face on the answer sheet. The reliability coefficient in the first measurement was acceptable at $\alpha=0.70$ (13 items).

Reading fluency was assessed using a part of the standardised first-grade reading test Allu (Lindeman 1998). The test contains 80 items. In each item, a child needs to select the correct word among four phonologically similar written alternatives corresponding to an adjoining picture that illustrates one of the words. The time limit for the test is 5 minutes. The raw sum score of the test was used, and the reliability (Kuder-Richardson) reported in the test manual was 0.97.

\section{Procedure}

Mathematical and IR skills were assessed three times: just before the instruction phase (T1, September); immediately after the instruction phase (T2, December); and 3 months after the instruction phase (T3, March). Language skills were assessed twice (at T1 and T2). The assessment sessions were held during the school day and required approximately three 45-minute sessions on separate days. Two members of the research team and three trained, qualified teachers with several years of teaching experience conducted all assessment sessions; each assessor was responsible for all the assessments conducted with a particular child.

\section{Intervention}

The counting skills intervention programme focuses on practicing verbal (oral) and object counting skills in the number range 1-20 (see Appendix) in small groups of children. The theoretical framework for the programme is based on the model of development of core numeracy skills by Aunio and Räsänen (2015). Thus, the content and the approach of the programme relies more on the developmental knowledge of skills development than curriculum standards. The programme applies explicit teaching and uses visual representations of mathematical concepts according to the concrete-representational-abstract levels, as these have been found to be beneficial instructional elements for children performing poorly. Structuring numbers is a key element in representing quantities (i.e. using structured dot cards and 10 frames) in the programme. The instruction manual with detailed activities and procedures includes 12 lesson plans of about 45 minutes each. Each lesson is composed of a teacher-guided activity that introduces the new mathematical subject, peer activities (e.g. games), and a short paper-and-pencil individual activity. The manipulatives are printable material (e.g. dot and place value cards) included in the manual or low-cost, everyday materials that can be found in every classroom (e.g. cubes, egg cartoons). 
In addition to the first author, one qualified female specialneeds teacher with 20 years of teaching experience volunteered to give intervention lessons. The intervention programme was introduced for that teacher in a professional development day of 6 hours given by the research team. Intervention sessions were held in small groups of five to six children. Following the advice of Gresham and colleagues (2000) concerning indirect assessment methods of treatment integrity, we asked the teachers to fill out a structured logbook sheet for every lesson given in order to assess whether they implemented the instruction as intended. In the logbook, the total amount of time in minutes used for every lesson was reported, and the functionality of every activity in the lesson was rated $(1=$ not good, 2 = good, $3=$ very good, or $\mathrm{x}=$ not completed).

\section{Data analysis}

Throughout the analysis process, parametric analyses were applied. However, because of the small sample sizes, the results were confirmed using non-parametric analyses. For the sake of simplicity, if the results from parametric and nonparametric analyses did not significantly contradict each other, only the results from the parametric analyses were reported. The preliminary analysis examined the normality of the test scales and the children's demographic variables. In the main analysis, we first focused on analysing mathematical performance between the groups at $\mathrm{T} 1$, followed by development from $\mathrm{T} 1$ to $\mathrm{T} 2$, and then from $\mathrm{T} 1$ to $\mathrm{T} 3$. The gain scores for each measure were calculated by subtracting the T1 score from the T2 or T3 score. The mathematics learning background was examined by calculating correlations across samples among the mathematics, IR and language scales. Furthermore, IR and language performance differences between the groups were analysed at different measurement times.

\section{Results}

\section{Preliminary analysis}

The Shapiro-Wilk test showed that the mathematics combined scale and the IR scales were normally distributed, $W(135)=0.96, p>0.05$ in both scales. The addition and subtraction scales showed non-normal distribution, both having negative kurtosis ( -0.29 and -0.91 , respectively). The subtraction scale was positively skewed. This indicated a greater number of low scores in the sample than we expected; children at the beginning of the first grade could complete only a few written addition and subtraction calculations. Both language scales were significantly non-normal. The listening comprehension scale showed a negative skewness of -1.65 , indicating a near-ceiling effect. The reading fluency scale showed a positive skewness of $1.24 ; 19.1 \%$ of the children were able to read only five or fewer words at the beginning of the first grade.

The results of the analysis of variance (ANOVA) found no difference in age among the LOWi, LOWc and TYPc groups, $F(2,148)=1.90, p>0.05$. For gender, there was a statistically significant different representation of boys and girls between the LOWc and TYPc groups, $\chi^{2}(1)=13.25, p<0.001$; in the LOWc group, girls were in the majority. Regarding Finnish and other languages spoken at home, no differences were found among the three groups, $\chi^{2}(2)=1.77, p>0.05$. The three groups did not differ with respect to the father's educational level, $F(2,124)=2.52, p>0.05$. ANOVA indicated a significant difference in the mother's educational level among the groups, $F(2,127)=3.22, p<0.05$; however, the finding was not confirmed by the Bonferroni-adjusted multiple comparisons or in the non-parametric analysis using the Kruskal-Wallis test. The three groups seemed rather equal regarding their demographics, and for this reason, none of these variables was used as a covariate in further analyses.

\section{Main analysis}

Mathematical skills: Separate ANOVAs (significance level of alpha set at $0.05 / 3=0.017$ to reduce Type I error) with posthoc comparisons with Bonferroni-adjusted corrections were conducted for the T1 mathematics scales in order to determine possible differences in the groups' performance before the instruction phase. The TYPc group outperformed both the LOWi and LOWc groups in the mathematics combined scale as well as in the addition and subtraction facts scales (Table 2). There were no performance differences between the LOWi and LOWc groups in any mathematics scale at T1, thus making groups comparable regarding initial level of mathematical skills.

To examine the effectiveness of intervention, differences in the mathematics gain scores among the groups were analysed using ANOVAs (significance level of alpha set at $0.05 / 3=0.017$ ) with post-hoc comparisons with Bonferroni-adjusted corrections (Table 2). From T1 to T2, statistically significant differences were found on the mathematics combined scale: the LOWi group had gained statistically significantly more compared to the LOWc and TYPc groups, with large effects of $g=1.06$ and $g=0.78$, respectively. This gain in favour of LOWi group can be interpreted as an effect of intervention. Despite its improvement, the LOWi group was unable to reach the performance level of the TYPc group at T2.

The gains in the mathematics combined scale at T1 to T3 showed that both LOW groups had improved statistically significantly more than the TYPc group did, with moderate effects. Nevertheless, the performance level of both LOW groups in the mathematics combined scale at T3 was similar to the performance level of TYPc at T1. In the addition and subtraction facts scales, no statistically significant differences were found between the groups on gain scores from T1 to T2 or from T1 to T3. Thus, practicing counting skills had no significant effect for improvement in basic skills in arithmetic.

Inductive reasoning and language skills: The intercorrelation matrix of the mathematics, IR and language scales is presented in Table 3. The Pearson's correlation coefficient test 
TABLE 2: Means, standard deviations and effect sizes for the mathematics scales at Time 1, 2 and 3 by group.

\begin{tabular}{|c|c|c|c|c|c|c|c|c|c|c|c|c|}
\hline \multirow[t]{2}{*}{ Measure } & \multicolumn{2}{|c|}{$\frac{\text { LOW }}{\text { intervention }(\mathrm{A})}$} & \multicolumn{2}{|c|}{$\begin{array}{c}\text { LOW } \\
\text { control (B) }\end{array}$} & & $\begin{array}{l}\text { TYP } \\
\text { ntrol (C) }\end{array}$ & \multirow[t]{2}{*}{$F(d f 1, d f 2)$} & \multirow[t]{2}{*}{$p$} & \multirow[t]{2}{*}{$\begin{array}{c}\text { Pairwise } \\
\text { comparisons } \dagger\end{array}$} & \multirow[t]{2}{*}{$\begin{array}{l}\text { ES: }(g) \\
\text { A vs. B }\end{array}$} & \multirow[t]{2}{*}{$\begin{array}{l}\text { ES }(g) \\
\text { A vs. C }\end{array}$} & \multirow[t]{2}{*}{$\begin{array}{l}\text { ES }(g) \\
\text { B vs. C }\end{array}$} \\
\hline & $n$ & M (SD) & $n$ & M (SD) & $n$ & M (SD) & & & & & & \\
\hline \multicolumn{13}{|c|}{ Combined scale (max. 42 p.) } \\
\hline Time 1 & 11 & $12.91(4.18)$ & 26 & $13.85(3.84)$ & 114 & $27.82(5.09)$ & $120.99(2,148)$ & $* * *$ & $A=B<C$ & - & - & - \\
\hline Time 2 & 11 & $22.09(5.30)$ & 26 & $18.77(6.57)$ & 114 & $33.05(5.31)$ & $81.86(2,148)$ & $* * *$ & $A=B<C$ & - & - & - \\
\hline Time 3 & 11 & $27.36(4.99)$ & 26 & $26.50(7.26)$ & 107 & $36.92(4.48)$ & $54.30(2,141)$ & $* * *$ & $A=B<C$ & - & - & - \\
\hline Gain Time 1-Time 3 & 11 & $14.45(5.61)$ & 26 & $12.65(5.55)$ & 107 & $9.36(5.01)$ & $8.04(2,141)$ & $* * *$ & $A=B>C$ & 0.45 & 1.01 & 0.67 \\
\hline \multicolumn{13}{|c|}{ Addition facts (max. 40 p.) } \\
\hline Time 1 & 11 & $6.73(3.74)$ & 26 & $5.54(4.59)$ & 114 & $12.54(5.53)$ & $22.30(2,148)$ & $* * *$ & $A=B<C$ & - & - & - \\
\hline Time 2 & 11 & $16.82(3.43)$ & 26 & $14.23(5.87)$ & 114 & $20.23(5.10)$ & $15.40(2,148)$ & $* * *$ & $A=B, A=C, B<C$ & - & - & - \\
\hline Time 3 & 11 & $19.18(2.75)$ & 26 & $18.65(5.87)$ & 107 & $25.71(6.01)$ & $19.39(2,141)$ & $* * *$ & $A=B<C$ & - & - & - \\
\hline Gain Time 1-Time 2 & 11 & $10.09(3.33)$ & 26 & $8.69(6.16)$ & 114 & $7.69(6.29)$ & $0.95(2,148)$ & ns & $A=B=C$ & 0.31 & 0.44 & 0.19 \\
\hline Gain Time 1-Time 3 & 11 & $12.45(4.10)$ & 26 & $13.12(7.00)$ & 107 & $13.14(6.47)$ & $0.06(2,141)$ & ns & $A=B=C$ & -0.15 & -0.13 & 0.00 \\
\hline Time 1 & 11 & $1.73(2.76)$ & 26 & $1.00(2.04)$ & 114 & $7.00(6.00)$ & $16.35(2,148)$ & $* * *$ & $A=B<C$ & - & - & - \\
\hline Time 2 & 11 & $12.09(6.95)$ & 26 & $11.85(5.18)$ & 114 & $17.25(4.68)$ & $16.15(2,148)$ & $* * *$ & $A=B<C$ & - & - & - \\
\hline Time 3 & 11 & $14.27(4.32)$ & 26 & $14.65(5.34)$ & 107 & $19.65(5.56)$ & $12.17(2,141)$ & $* * *$ & $A=B<C$ & - & - & - \\
\hline Gain Time 1-Time 2 & 11 & $10.36(8.16)$ & 26 & $10.85(5.45)$ & 114 & $10.25(6.80)$ & $0.09(2,148)$ & ns & $A=B=C$ & -0.21 & 0.02 & 0.11 \\
\hline Gain Time 1-Time 3 & 11 & $12.54(5.87)$ & 26 & $13.65(6.28)$ & 107 & $12.57(6.96)$ & $0.27(2,141)$ & ns & $A=B=C$ & -0.47 & 0.00 & 0.20 \\
\hline
\end{tabular}

LOW, low-performing; TYP, typically performing.

$\dagger$, Analysis of variance test post-hoc pairwise comparisons: significant differences between groups $(p<0.05)$ marked as $>$ or $<$, and no difference between groups marked as $=$.

\#, ES = Effect size $(g)$ calculated as the difference of the mean Time 1 - Time 2 and Time 1 - Time 3 change in the intervention group and the mean Time $1-$ Time 2 and Time $1-$ Time 3 change in the control group, divided by the pooled within-group Time 1 standard deviation.

$* * * p<0.001, * * p<0.01, n s=$ non-significant.

TABLE 3: Intercorrelation matrix of mathematics, inductive reasoning and language skills at assessment Times 1, 2 and 3.

\begin{tabular}{|c|c|c|c|c|c|c|c|c|c|c|c|c|c|c|c|}
\hline Variable & 1 & 2 & 3 & 4 & 5 & 6 & 7 & 8 & 9 & 10 & 11 & 12 & 13 & 14 & 15 \\
\hline 1. Mathematics combined scale T1 & - & - & - & - & - & - & - & - & - & - & - & - & - & - & - \\
\hline 2. Mathematics combined scale $\mathrm{T} 2$ & 0.81 & - & - & - & - & - & - & - & - & - & - & - & - & - & - \\
\hline 3. Mathematics combined scale T3 & 0.73 & 0.81 & - & - & - & - & - & - & - & - & - & - & - & - & - \\
\hline 4. Addition facts $\mathrm{T} 1$ & 0.65 & 0.55 & 0.46 & - & - & - & - & - & - & - & - & - & - & - & - \\
\hline 5. Addition facts $\mathrm{T} 2$ & 0.49 & 0.51 & 0.50 & 0.45 & - & - & - & - & - & - & - & - & - & - & - \\
\hline 6. Addition facts T3 & 0.57 & 0.60 & 0.65 & 0.48 & 0.70 & - & - & - & - & - & - & - & - & - & - \\
\hline 7. Subtraction facts $\mathrm{T} 1$ & 0.51 & 0.41 & 0.39 & 0.62 & 0.27 & 0.38 & - & - & - & - & - & - & - & - & - \\
\hline 8. Subtraction facts $\mathrm{T} 2$ & 0.51 & 0.51 & 0.51 & 0.43 & 0.81 & 0.69 & 0.31 & - & - & - & - & - & - & - & - \\
\hline 9. Subtraction facts $T 3$ & 0.46 & 0.41 & 0.54 & 0.39 & 0.51 & 0.67 & 0.35 & 0.53 & - & - & - & - & - & - & - \\
\hline 10. Inductive reasoning skills T1 & 0.36 & 0.36 & 0.35 & 0.31 & 0.16 & $\underline{0.19}$ & 0.26 & 0.22 & 0.12 & - & - & - & - & - & - \\
\hline 11. Inductive reasoning skills T2 & 0.40 & 0.42 & 0.45 & 0.29 & 0.23 & 0.35 & $\underline{0.21}$ & 0.34 & 0.27 & 0.68 & - & - & - & - & - \\
\hline 12. Inductive reasoning skills T3 & 0.40 & 0.40 & 0.45 & 0.29 & 0.26 & 0.33 & $\underline{0.20}$ & 0.29 & 0.37 & 0.53 & 0.63 & - & - & - & - \\
\hline 13. Reading fluency $\mathrm{T} 1$ & 0.56 & 0.49 & 0.47 & 0.48 & 0.36 & 0.46 & 0.41 & 0.36 & 0.37 & 0.35 & 0.36 & 0.39 & - & - & - \\
\hline 14. Reading fluency $\mathrm{T} 2$ & 0.50 & 0.51 & 0.53 & 0.42 & 0.40 & 0.52 & 0.33 & 0.42 & 0.43 & 0.42 & 0.45 & 0.45 & 0.85 & - & - \\
\hline 16. Listening comprehension $\mathrm{T} 2$ & $\underline{0.17}$ & $\underline{0.17}$ & $\underline{0.19}$ & 0.01 & 0.05 & 0.10 & -0.03 & 0.15 & 0.07 & 0.31 & 0.39 & 0.30 & 0.24 & 0.60 & 0.28 \\
\hline
\end{tabular}

Values in bold: $p<0.01$, values underlined: $p<0.05$, otherwise non-significant.

showed that, at $\mathrm{T} 1$ and $\mathrm{T} 2$, performance on the reading fluency scale correlated moderately with performance on the mathematics combined scale and correlated weakly with performance on the addition and subtraction scales. Performance in listening comprehension correlated only weakly with performance on the mathematics combined scale, but not statistically significantly with performance on the addition and subtraction facts scales. The IR scale showed a mainly weak correlation with all three mathematics scales at all three times.

A set of ANOVAs (significance level of alpha set at $0.05 / 3=0.017$ ) was conducted with Bonferroni-adjusted post-hoc tests, which revealed that the TYPC group outperformed both LOW groups in the IR and reading fluency scales at every assessment time point (Table 4). The developmental growth rate seemed similar in every group because no statistically significant differences among the groups were revealed in comparing the gain scores. The three groups did not differ in their listening comprehension scores at any time point.

Intervention implementation: Both teachers implemented all lessons and tasks in the manual in 12 sessions over 8 weeks. The average lesson time in minutes was 44.6 $(\mathrm{SD}=3.6)$. In both instruction groups, some lessons were conducted during school hours and some before or after school hours so that instruction could be feasibly integrated as part of the schoolwork. Both teachers reported that the functionality of the tasks was good or very good. 
TABLE 4: Means, standard deviations and effect sizes for inductive reasoning and language skills by group

\begin{tabular}{|c|c|c|c|c|c|c|c|c|c|c|c|c|}
\hline \multirow[t]{3}{*}{ Measure } & \multirow{2}{*}{\multicolumn{2}{|c|}{$\begin{array}{c}\text { LOW } \\
\text { Intervention (A) }\end{array}$}} & \multirow{2}{*}{\multicolumn{2}{|c|}{$\begin{array}{c}\text { LOW } \\
\text { Control (B) }\end{array}$}} & & TYP & \multirow[t]{3}{*}{$F(d f 1, d f 2)$} & \multirow[t]{3}{*}{$p$} & \multirow{3}{*}{$\begin{array}{c}\text { Pairwise } \\
\text { comparisons } \dagger\end{array}$} & \multirow{3}{*}{$\begin{array}{l}\mathrm{ES}^{\ddagger}(g) \\
\text { A vs. B }\end{array}$} & \multirow{3}{*}{$\begin{array}{l}\text { ES }(g) \\
\text { A vs. C }\end{array}$} & \multirow[t]{3}{*}{$\begin{array}{l}\text { ES }(g) \\
\text { B vs. C }\end{array}$} \\
\hline & & & & & \multicolumn{2}{|c|}{ Control (C) } & & & & & & \\
\hline & $n$ & M (SD) & $\bar{n}$ & M (SD) & $n$ & M (SD) & & & & & & \\
\hline \multicolumn{13}{|c|}{ Inductive reasoning skills (max. 27 p.) } \\
\hline Time 1 & 10 & $15.40(4.81)$ & 23 & $16.30(3.51)$ & 103 & $18.78(3.68)$ & $6.94(2,133)$ & $* *$ & $A=B<C$ & - & - & - \\
\hline Time 2 & 10 & $16.70(4.92)$ & 23 & $18.22(3.63)$ & 103 & $20.22(3.46)$ & $7.29(2,133)$ & $* *$ & $A=B<C$ & - & & - \\
\hline Time 3 & 10 & $18.20(4.49)$ & 23 & $19.43(3.82)$ & 99 & $22.13(2.87)$ & $11.99(2,129)$ & $* * *$ & $A=B<C$ & - & - & - \\
\hline Gain Time 1-Time 2 & 10 & $1.30(3.20)$ & 23 & $1.91(3.17)$ & 103 & $1.44(3.07)$ & $0.34(2,132)$ & ns & $A=B=C$ & -0.15 & -0.04 & 0.13 \\
\hline Gain Time 1-Time 3 & 10 & $2.80(2.57)$ & 23 & $3.13(3.52)$ & 99 & $3.28(3.33)$ & $0.41(2,129)$ & ns & $A=B=C$ & -0.06 & -0.13 & -0.04 \\
\hline \multicolumn{13}{|c|}{ Listening comprehension (max. 13 p.) } \\
\hline Time 1 & 10 & $9.80(2.62)$ & 25 & $9.64(3.11)$ & 106 & $10.17(2.31)$ & $0.51(2,138)$ & ns & $A=B=C$ & - & - & - \\
\hline Time 2 & 10 & $9.80(1.87)$ & 25 & $10.80(1.58)$ & 106 & $11.27(1.69)$ & $3.94(2,138)$ & ns & $A=B=C$ & - & - & - \\
\hline Gain Time 1-Time 2 & 10 & $0.00(3.37)$ & 25 & $1.16(2.51)$ & 106 & $1.10(2.51)$ & $0.88(2,138)$ & ns & $A=B=C$ & -0.38 & -0.47 & 0.02 \\
\hline \multicolumn{13}{|c|}{ Reading fluency (max. 80 p.) } \\
\hline Time 1 & 10 & $12.10(9.53)$ & 25 & $7.96(7.55)$ & 106 & $25.63(17.70)$ & $14.31(2,138)$ & $* * *$ & $A=B<C$ & - & - & - \\
\hline Gain Time 1-Time 2 & 10 & $10.30(8.93)$ & 25 & $13.32(7.51)$ & 106 & $13.64(10.23)$ & $0.58(2,138)$ & ns & $A=B=C$ & -0.36 & -0.19 & -0.02 \\
\hline
\end{tabular}

LOW, low-performing; TYP, typically performing.

$\dagger$, Analysis of variance test post-hoc pairwise comparisons: significant differences between groups $(p<0.05)$ marked as $>$ or $<$, and no difference between groups marked as $=$

\#, ES, Effect size $(\mathrm{g})$ calculated as the difference of the mean Time 1 - Time 2 and Time 1 - Time 3 change in the intervention group and the mean Time $1-$ Time 2 and Time 1 - Time 3 change in the control group, divided by the pooled within-group Time 1 standard deviation.

$* * p<0.01 ; * * * p<0.001 ;$ ns, non-significant.

\section{Discussion}

The purpose of this study was to investigate whether lowperforming children's mathematical skills could be improved using ThinkMath intervention programme. In addition, relations between IR, language, and mathematical skills were examined. In 2 months, the low-performing first graders who received intervention in addition to their core mathematics instruction improved significantly more in their mathematical skills compared to their low- and typically performing peers who did not receive intervention. Irrespective of their improvement, the low-performing children were unable to achieve the same level as their typically performing peers did. In addition to low performance in mathematical skills, these children showed lower performance in their IR and reading fluency skills than the TYP children at all measurement points.

We would like to emphasise that it was possible to increase low-performing children's performance in mathematical skills, although the intervention phase was shorter in duration compared to that reported in previous intervention studies (Bryant et al. 2008a; 2008b; 2011; Fuchs et al. 2005; 2006). Explicit teaching in small groups, applying the CRA approach in representing mathematical concepts and using structuring of numbers were found to be the potential effective instructional features of the intervention programme, as found also in previous studies for boosting the mathematical skills of the LOW children (Bryant et al. 2008a, 2011). This educational approach seemed to meet the needs of our low-performing children at the beginning of formal schooling. Moreover, the implementation of the intervention did not require a long professional training for the teachers. Thus, special-needs teachers would be able to integrate it as part of their mathematics intensified instruction with relatively easy. In a context such as, for example, South African public schools, the intervention programme can be adapted to serve a whole class in schools where many children struggle at the beginning of the first grade (see the work by Ragpot, Mononen \& Aunio, in press).

No intervention effect was shown in the children's development of arithmetical skills. Even though counting skills are seen as one strong predictor for arithmetical skills (e.g. Desoete et al. 2009), we found no transfer effect. This may be because of a relatively short period ( 3 months) of time between the end of the intervention and the follow-up measurement. The results of this study also indicate that there appears to be a challenge of long-lasting effects of intervention. The growth in the mathematical skills development of the LOWi group slowed down after the intervention ended, in other words, there was no response maintenance. Regardless of the improvement of the lowperforming children, the gap between them and the typically performing children still existed after the intervention. In fact, 3 months after the intervention phase, the performance in mathematical skills of both LOW groups was at the level of the performance of their TYP peers at the beginning of the school year. These results highlight the fact that some low-performing children most likely will need continuous educational support and underline the need for continuous progress monitoring (Olson et al. 2007).

In the future studies, in order to find the intervention with a long-lasting effect to support children, it would be of interest to add more sessions into the programme, to be given either more frequently (e.g. three times per week) or for a longer period of duration (e.g. two times per week for 3 months, or once a week after a 2 -month period). Additional sessions would allow to focus more deeply and to do repetition on the content included in the current programme, thus probably strengthening the skills even more. Furthermore, some of the 
tasks might be adjusted to better meet the everyday mathematics of children (e.g. using more examples of counting-related tasks in everyday life). Of interest would also be to emphasise small-group and classroom teachers' cooperation: that children would be reminded to use their newly learned skills in small-group instruction also in their regular mathematics lessons.

Along with showing low performance in mathematical skills in the beginning of the first grade, these children also demonstrated weaker performance in their IR and reading fluency skills compared to the TYP children, thus indicating the accumulation of problems in the same children. This is in line with the literature showing that mathematical difficulties are often comorbid, for example, with reading difficulties (Gross-Tsur, Manor \& Shalev 1996). Thus, learning of mathematical skills might have been more challenging for these children compared to having weakness only in mathematical skills.

The present study has some limitations, such as, the small number of participants involved in the study, the lack of randomisation in the intervention and the control groups, absence of an active control group receiving another type of intervention and inadequate measures of fidelity. To address these shortcomings, further research is warranted to investigate the findings reported here in more detail by employing a larger sample, randomisation of groups, using active control groups in addition to passive ones and use of observations or video recordings in classrooms.

\section{Conclusion}

This study complemented previous research by developing and determining the effects of counting skills intervention programmes for low-performing first graders. A relatively short phase of intensified support on practicing counting skills was beneficial in increasing the early mathematical skills of low-performing children. Our results indicated that some low-performing children would most likely benefit from on-going supplemental support in order to maintain a positive development in mathematical skills.

\section{Acknowledgements}

The research reported here was part of the ThinkMath project, which was supported by the Finnish Ministry of Education and Culture (2011-2015). The opinions expressed are those of the authors and do not represent views of the Finnish Ministry of Education and Culture. We wish to thank all the participating teachers and children.

\section{Competing interests}

The authors declare that they have no financial or personal relationships, which may have inappropriately influenced them in writing this article.

\section{Authors' contributions}

Both authors contributed equally to the writing of this article.

\section{References}

Aunio, P. \& Mononen, R., 2012, Assessment of mathematics skills in the first grade, Unpublished.

Aunio, P. \& Niemivirta, M., 2010, 'Predicting children's mathematical performance in grade one by early numeracy', Learning and Individual Differences 20(5), 427-435. http://dx.doi.org/10.1016/j.lindif.2010.06.003

Aunio, P. \& Räsänen, P., 2015, 'Core numerical skills for learning mathematics in children aged five to eight years - A working model for educators', European Early Childhood Education Research Journal. Advance online publication. http://dx.doi. org/10.1080/1350293X.2014.996424

Basic Education Act 628/1998, Amendment 642/2010, viewed 20 January 2016, from http://www.finlex.fi/fi/laki/kaannokset/1998/en19980628.pdf

Björn, P.M., Aro, M.T., Koponen, T.K., Fuchs, L.S. \& Fuchs, D.H., 2015, 'The many faces of special education within RTI frameworks in the United States and Finland', Learning Disability Quarterly. Advance online publication. http://dx.doi. org $/ 10.1177 / 07319487155947878$

Bryant, D.P., Bryant, B.R., Gersten, R.M., Scammacca, N.N. \& Chavez, M.M., 2008a, 'Mathematics intervention for first- and second-grade students with mathematics difficulties: The effects of Tier 2 intervention delivered as booster lessons', Remedial and Special Education 29(1), 20-32. http://dx.doi.org/10.1177/ 0741932507309712

Bryant, D.P., Bryant, B.R., Gersten, R.M., Scammacca, N.N., Funk, C., Winter, A., et al., $2008 \mathrm{~b}$, 'The effects of Tier 2 intervention on the mathematics performance of first-grade students who are at risk for mathematics difficulties', Learning Disability Quarterly 31, 47-63.

Bryant, D.P., Bryant, B.R., Roberts, G., Vaughn, S., Hughes Pfannelstiel, K., Porterfield, J., et al., 2011, 'Early numeracy intervention program for first-grade students with mathematics difficulties', Exceptional Children 78(1), 7-23.

Clarke, B., Doabler, C.T., Strand Cary, M., Kosty, D., Baker, S., Fien, H., et al., 2014 'Preliminary evaluation of a Tier 2 mathematics intervention for first-grade students: Using a theory of change to guide formative evaluation activities', School Psychology Review 43(2), 160-178.

Desoete, A., Stock, P., Schepens, A., Baeyens, D. \& Roeyers, H., 2009, 'Classification, seriation, and counting in grades 1, 2, and 3 as two-year longitudinal predictors for low achieving in numerical facility and arithmetical achievement?', Journal of Psychoeducational Assessment 27(3), 252-264. http://dx.doi.org/10.1177/ 0734282908330588

Finnish National Board of Education (FNBE), 2004, National Core Curriculum for Basic Education 2004, viewed 10 January 2016, from http://www.oph.fi/english/ curricula_and_qualifications/basic_education

Finnish National Board of Education (FNBE), 2010, Amendments and additions to the National Core Curriculum for Basic Education, viewed 10 January 2016, from: http://www.oph.fi/download/132551_amendments_and_additions_to_ national_core_curriculum_basic_education.pdf

Fuchs, L.S., Compton, D.L., Fuchs, D., Paulsen, K., Bryant, J.D. \& Hamlett, C.L., 2005, 'The prevention, identification, and cognitive determinants of math difficulty', Journal of prevention, identification, and cognitive determinants of math difficulty', Journal of
Educational Psychology 97(3), 495-513. http://dx.doi.org/10.1037/0022-0663.97.3.493

Fuchs, L.S., Fuchs, D., Hamlet, C.L., Powell, S.R., Capizzi, A.M., \& Seethaler, P.M., 2006, 'The effects of computer-assisted instruction on number combination skill in atrisk first graders', Journal of Learning Disabilities 39(5), 467-475. http://dx.doi.or $\mathrm{g} / 10.1177 / 00222194060390050701$

Geary, D.C., 2013, 'Early foundations for mathematics learning and their relations to learning disabilities', Current Directions in Psychological Science 22(1), 23-27. http://dx.doi.org/10.1177/0963721412469398

Gresham, F.M., MacMillan, D.L., Beebe-Frankenberger, M.E. \& Bocian, K.M., 2000 'Treatment integrity in learning disabilities intervention research: Do we really know how treatments are implemented?', Learning Disabilities Research \& Practice 15(4), 198-205. http://dx.doi.org/10.1207/SLDRP1504_4

Gross-Tsur, V., Manor, O. and Shalev, R.S., 1996, 'Developmental dyscalculia: Prevalence and demographic features', Developmental Medicine \& Child Neurology 38, 25-33. http://dx.doi.org/10.1111/j.1469-8749.1996.tb15029.x

Hotulainen, R., Mononen, R. \& Aunio, P., 2012, Assessment of thinking skills in the first grade, Unpublished.

Jordan, N.C., Hanich, L.B. \& Kaplan, D., 2003, 'A longitudinal study of mathematical competencies in children with specific mathematics difficulties versus children with comorbid mathematics and reading difficulties', Child Development 74(3), 834-850. http://dx.doi.org/10.1111/1467-8624.00571

Kajamies, A., Poskiparta, E., Annevirta, T., Dufva, M., \& Vauras, M., 2003, YTTE. Luetun ja kuullun ymmärtämisen ja lukemisen sujuvuuden arviointi [Assessment of reading and listening comprehension and reading fluency], University of Turku, Oppimistutkimuksen keskus (OTUK), Turku.

Klauer, K.J., 1989, Denktraining für Kinder I [Thinking skills training for children I], Hogrefe, Göttingen.

Lindeman, J., 1998, Ala-asteen lukutesti ALLU [Reading test], University of Turku, Oppimistutkimuksen keskus (OTUK), Turku.

Mononen, R. \& Aunio, P., 2016, ThinkMath counting skills intervention programme, viewed 15 January 2015 from http://blogs.helsinki.fi/thinkmath

Morgan, P.L., Farkas, G. \& Wu, Q., 2009, 'Five-year growth trajectories of kindergarten children with learning difficulties in mathematics', Journal of Learning Disabilities 42, 306-321. http://dx.doi.org/10.1177/0022219408331037

Olson, S.C., Daly, E.J., III, Andersen, M., Tuner, A. \& Le Clair, C., 2007, 'Assessing student response to intervention, in S.R. Jimerson, M.K. Burns \& A.M. VanDerHeyden (eds.), Handbook of response to intervention, pp. 117-129, Springer, New York. 
Ragpot, L., Mononen, R. \& Aunio, P., in press. A mathematics learning support programme for grade one low performers in Gauteng schools: A pilot study with 400 learners, Centre for Education Practice Research, University of Johannesburg,
Johannesburg.

Sarama, J. \& Clements, D.H., 2009, Early childhood mathematics education research Learning trajectories for young children, Routledge, New York.

Smith, T.M., Cobb, P., Farran, D.C., Cordray, D.S. \& Munter, C., 2013, 'Evaluating math recovery: Assessing the causal impact of a diagnostic tutoring program on studen achievement', American Educational Research Journal 50(2), 397-428. http:// dx.doi.org/10.3102/0002831212469045
Toll, S.W.M. \& Van Luit, J.E.H., 2014, 'Explaining numeracy development in weak performing kindergartners', Journal of Experimental Child Psychology 124 97-111. http://dx.doi.org/10.1016/j.jecp.2014.02.001

Wright, R.J., Martland, J., Stafford, A.K. \& Stanger, G., 2002, Teaching number: Advancing children's skills and strategies, 2nd edn., Paul Chapman Publishing Ltd, London.

Yang, D.-C., Lai, M.-L., Yao, R.-F. \& Huang, Y.-C., 2014, 'Effects of remedial instruction on low-SES \& low-math students' mathematics competence, interest and confidence', Journal of Education and Learning 3(1), 1-15. http://dx.doi.org/10.5539/jel. v3n1p1 


\section{Appendix 1}

TABLE 1-A1: Content of the counting skills intervention programme.

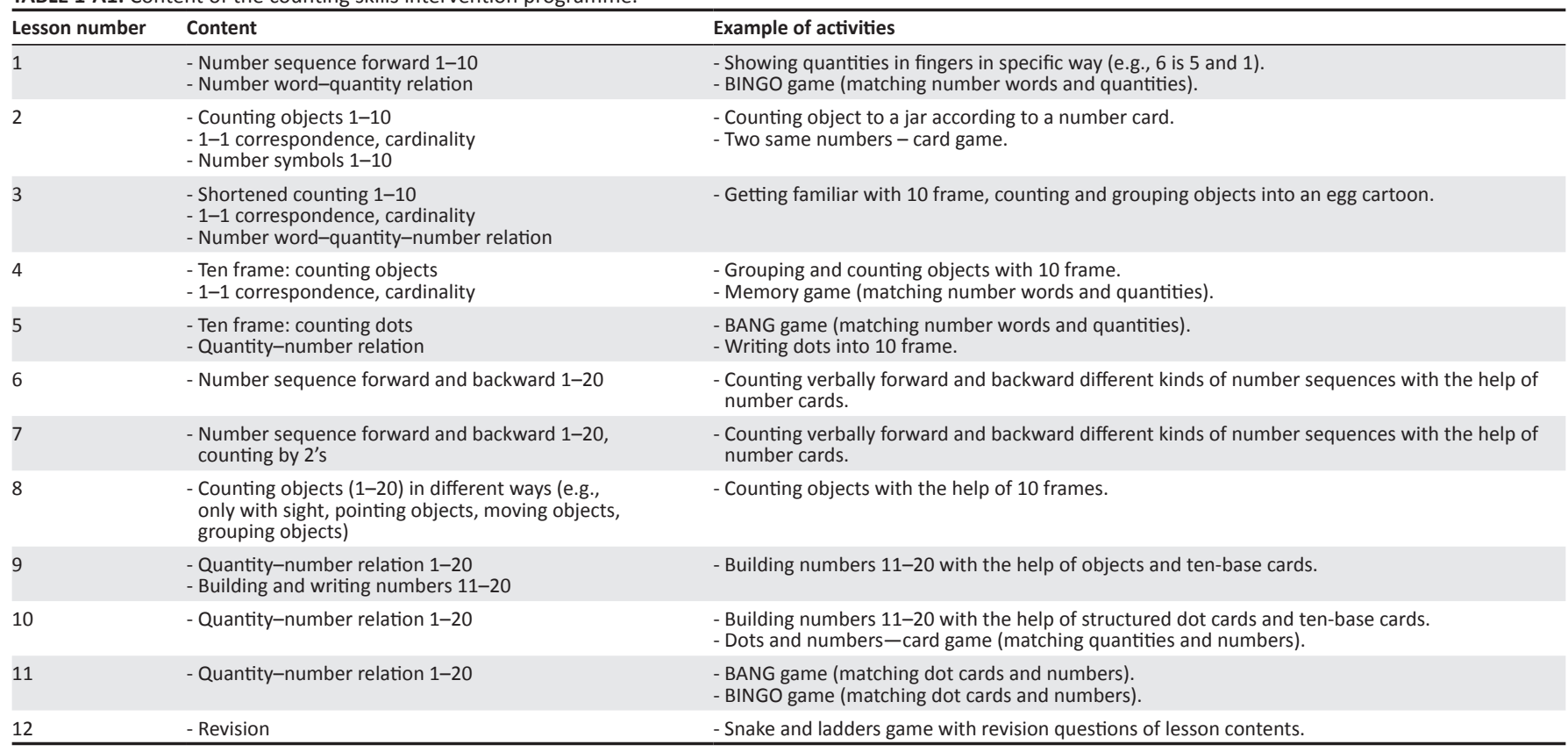

